\title{
Retinopathy of prematurity risk factors: Does human milk prevent retinopathy of prematurity?
}

\author{
Ayşe İpek Akyüz-Ünsal ${ }^{1}$, Özge Key ${ }^{1}$, Duygu Güler ${ }^{1}$, Sinan Bekmez ${ }^{1}$, Mehtap Sagus ${ }^{1}$, \\ Abdullah Barış Akcan², İmran Kurt-Omurlu³, Ayşe Anık², Sema Oruç-Dündar ${ }^{2}$, Münevver \\ Türkmen² \\ Departments of ${ }^{1}$ Ophthalmology, ${ }^{2}$ Neonatology and ${ }^{3}$ Biostatistics, Adnan Menderes University, Faculty of Medicine, Aydin. \\ E-mail: ipekunsal@yahoo.com
}

Received: 3rd March 2018, Revised: 28th May 2018, 1st August 2018, 12th September 2018, Accepted: 26th September 2018

SUMMARY: Akyüz-Ünsal Aİ, Key Ö, Güler D, Bekmez S, Sagus M, Akcan AB, Kurt-Omurlu I, Anık A, Oruç-Dündar S, Türkmen M. Retinopathy of prematurity risk factors: Does human milk prevent retinopathy of prematurity? Turk J Pediatr 2019; 61: 13-19.

The aim of this study was to investigate the risk factors for Retinopathy of Prematurity (ROP) development and the potential effect of human breast milk among these factors. For this purpose, infants admitted to a tertiary referral clinic for ROP screening and treatment between April 2013 and May 2015, were included in this retrospective study. The demographic data, accompanying diseases, previous surgery, type of feeding and duration of human breast milk intake were recorded. According to the ROP screening examination results, infants were divided into two groups as those with ROP (infants at any stage of ROP) and those without ROP. Relationship between the risk factors and ROP were evaluated. The comparison of 221 infants without ROP and 99 infants with ROP; revealed that gestational age at birth, birth weight, mechanical ventilation support, bronchopulmonary and cardiac diseases, hydrocephaly, any previous surgery, infections, steroid treatment percentages were high and human breast milk intake percentage was low among infants with ROP. Mean breast feeding time for infants with ROP $(3.81 \pm 2.33$ month) was shorter than the infants without ROP $(5.51 \pm 1.43$ month $)(\mathrm{p}<0.001)$. In logistic regression analysis, the duration of breast feeding was inversely related with ROP (OR 0.744; 95\% CI 0.621-0.891; $\mathrm{p}<0,001$ ). These results suggest that gestational age at birth and accompanying diseases are the main risk factors for the development of ROP. As the duration of the breast feeding of the infants without ROP was longer than the infants with ROP; breast feeding may have a preventive effect on ROP development.

Key words: breast feeding, human breast milk, retinopathy of prematurity, risk factors, ROP.

Retinopathy of prematurity (ROP) is one of the leading causes of childhood blindness in the developing world. Although epidemics are not seen due to the tight control of oxygen treatment at intensive care units, ROP incidence increases by the rising amount of surviving premature infants. ${ }^{1-7}$ ROP related ocular morbidities like refractive errors, strabismus, amblyopia, glaucoma, cataract, macular dragging, retinal breaks and detachment also have a tendency to increase. ${ }^{8-12}$ In an attempt to prevent ROP, known and possible risk factors are worth investigating.

In the literature, the accepted independent main risk factors are low gestational age at birth and low birth weight. Frequent blood transfusions, severe infections, intracranial hemorrhages, bronchopulmonary diseases and artificial ventilation are the other well-known important risk factors. ${ }^{1-7,13-18}$ These risk factors are closely related with the natural course of the disease. For example; immaturity of 
bone marrow, lymphoid tissue and liver is responsible from infections, hemorrhages and increased need of blood transfusion.. Immature bronchopulmonary tissue causes the prolonged need of artificial ventilation. However; gender and genetic properties determine the maturity of these tissues as well as eyes, so they are independent from the immaturity.

The other independent factor which may be the only variable factor is breast feeding according to our clinical observations and related literature. ${ }^{19-25}$ Human breast milk is indispensable for the maturation as it contains many immunogenic factors like epidermal growth factor (EGF), transforming growth factor (TGF) $\alpha, \beta 1-2$, ghrelin, lectin, adiponectin, erythropoietin and insulin-like growth factor-1(IGF-1). ${ }^{26-28}$ In order to assess the effect of human milk and to revisit the risk factors related with ROP, the records of our patients were retrospectively analyzed.

\section{Material and Methods}

This study was conducted at the Ophthalmology and Neonatology departments of Adnan Menderes University hospital between April 2013 and May 2015, all infants admitted during this period were enrolled in this retrospective study. The total number of infants was 320 and $173(54 \%)$ of them were male, $146(45 \%)$ of them were female and one of them had ambiguous genitalia. Not only the infants born at the university hospital, but also those referred from other state and private hospitals of neighboring cities were also enrolled in this study. Ethical approval was obtained from the local ethics committee (approval date: 28.01.2016, report number: 17).

Ophthalmologic examinations and staging for ROP were conducted by the same ophthalmologist. According to the International Committee for the Classification of ROP (ICROP) criteria; initial screening of infants born before 27 gestational weeks were done at the $31^{\text {th }}$ week of gestational age, and 4 weeks after birth for the infants which were born between 27-36 gestational weeks. ${ }^{29}$ The examinations were performed 1 hour after the instillation of Phenylephrine $1 \%$ and Tropicamide $0.5 \%$. Fundoscopic examinations were conducted using binocular indirect ophthalmoscope, +28 Diopter lens, pediatric speculum and a scleral depressor. Follow-up examinations and treatments were conducted depending on the ICROP and ETROP (Early Treatment of ROP randomized Trial) criteria. ${ }^{30}$

The data of neonates born between 24-32 gestational weeks weighing under 1500 grams were analyzed retrospectively. Infants born between 32-36 gestational age and were heavier than 1500 grams were also evaluated in the study according to the known risk factors that they were carrying, according to the national guideline. ${ }^{31}$ Infants were divided into two groups; first one was the 'without ROP' group which included 221 infants (69\%) without any signs of ROP, the second group was the "with ROP' group which included 99 infants $(31 \%)$ at stage 1, 2 and 3 ROP. None of the neonates developed stage 4, 5 ROP or Aggressive Posterior Retinopathy of Prematurity. All of the premature infants with the diagnosis of type 1 ROP were treated with argon laser photocoagulation only.

The medical history and possible risk factors including; gender, gestational age at birth, birth weight, APGAR scores at birth, mechanical ventilation support, cardiac diseases including patent ductus arteriosus, atrial septal defect, ventricular septal defect, patent foramen ovale, bronchopulmonary diseases including bronchopulmonary displasia, respiratory distress syndrome, pulmonary hypertension, pneumothorax, meconium aspiration syndrome, pneumonia, bronchiolitis and apnea attacks, intracranial pathologies including hydrocephaly and hemorrhage, blood transfusions (any kind of transfusion), infections (culture-proven), jaundice (necessitating phototherapy), previous surgical operations including inguinal hernia, hypospadias, hydrocelectomy, tracheostomy, ileostomy, shunt for hydrocephaly, PDA ligation and the type of feeding if it is only fresh or frozen human breast milk (donor milk not included), or together with formula feeding and the time period of breast feeding were compared between the 'with and without ROP' groups.

The Kolmogorov-Smirnov test was used to assess the normality of numeric variables. For the human milk intake time period variable that were not normally distributed, comparison between two groups was made by MannWhitney $U$ test and descriptive statistics are presented as median (25-75 percentiles). To 
analyze the categorical data, a chi-square test was used and descriptive statistics are presented as frequency (\%). The Spearman's rho correlation analysis was used to determine the correlation between the ROP level and breastfeeding time variables. We used logistic regression analysis to predict the neonates with ROP. The $\mathrm{p}$ values below 0.05 were considered statistically significant.

\section{Results}

Three hundred premature infants were enrolled in this study and 99 of them were infants with ROP at any stage and 221 of them were without ROP. The mean gestational age at birth of all infants in the study group was $31.5 \pm$ 3 (24-36) weeks and the mean birth weight was $1658 \pm 482$ (570-2800) grams. The mean gestational age at birth of infants with ROP was $28.77 \pm 2.99$ weeks and the mean gestational age at birth of infants without ROP was 32.8 \pm 2.1 weeks, the difference between them was statistically significant $(p<0.01)$. Similarly, the difference between the birth weight of infants with(1252.09 $\pm 442.68 \mathrm{~g})$ and without ROP $(1839.84 \pm 378.60 \mathrm{~g})$ was also significant $(p<0.001)$. APGAR scores at the first and fifth minutes of infants with ROP were $6.31 \pm 1.66$ $\& 6.95 \pm 1,06$ and those without ROP were $7.78 \pm 0.95 \& 8.48 \pm 0.74$; the difference between the two groups were statistically significant $(\mathrm{p}<0.001 ; \mathrm{p}<0.001)$. The association between ROP development and male gender was found to be significant $(p=0.012)$.

Among ROP group (99/320 cases); 62 (19.4\%) of the infants had stage $1,18(5.6 \%)$ of them had stage 2 and 19 (5.9\%) of them had stage 3 ROP. The percentage of the infants treated with laser was $5.9 \%$.

Mean breast feeding time for infants at any stage of ROP was $3.81 \pm 2.33$ (0-6) months and was $5.51 \pm 1.43(0-6)$ months $(\mathrm{p}<0.001)$ in infants without ROP. The correlation between duration of human breast milk intake and ROP development was significant. There was a negative and moderate correlation between duration of human breast milk intake and ROP development. ( $\mathrm{r}=0.461, \mathrm{p}<0.001)$ (Fig. 1).

The comparison of the infants with and without ROP for accompanying risk factors showed that cardiac and bronchopulmonary diseases, mechanical ventilation support, infections,

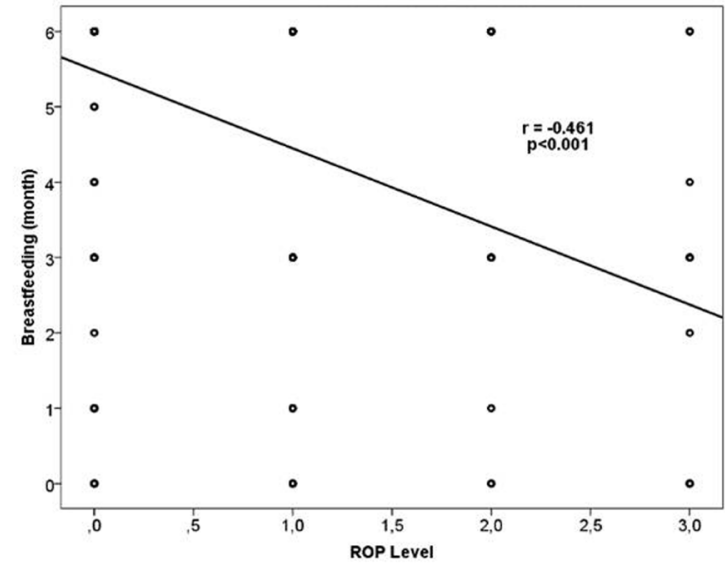

Fig. 1. Graph depicts the inverse relationship between breastfeeding/human milk intake time and ROP level.

steroids, hydrocephaly, any previous surgery and human breast milk intake were statistically significant as shown in Table I.

According to the logistic regression analysis; the most striking finding of this study was the inverse association of ROP development with duration of human breast milk intake [odds ratio (OR): $0.74,95 \%$ confidence interval $(\mathrm{CI})$ : $0.62-0.89, p=0.001]$. This finding was similar with the association of ROP development risk with gestational age at birth (OR: 0.63, 95\% CI: 0.54-0.73, $\mathrm{p}<0.001)$. Additionally, the risk of ROP development increased 3.2 times with mechanical ventilation support, 2.9 times with the accompanying cardiac diseases and 8.7 times with the bronchopulmonary diseases (Table II). In this study the discrimination percentage of the logistic regression analysis of the neonates with ROP was $75.8 \%$ and for those without ROP was $93.6 \%$. The overall accuracy of the model was $88.1 \%$.

\section{Discussion}

In this study, the relation between ROP and human breast milk among other well-known risk factors was investigated. The comparison of with ROP and without ROP groups revealed that human breast milk intake rate was lower among infants with ROP $(79.8 \%, 96.8 \%$, respectively, $\mathrm{p}<0.001$ ). Not only human breast milk intake, but also lower duration of human breast milk intake was a significant risk factor among other factors $(\mathrm{p}<0.001)$.

The other well-known risk factors were also evaluated and compared for their importance 
Table I. Determined Risk Factors of Infants with and without ROP.

\begin{tabular}{|c|c|c|c|c|c|}
\hline \multirow{2}{*}{$\begin{array}{l}\text { Risk factors } \\
\text { Ventilation support* }\end{array}$} & \multicolumn{2}{|c|}{$\begin{array}{c}\text { Neonates with ROP } \\
\text { (n: 99) }\end{array}$} & \multicolumn{2}{|c|}{$\begin{array}{c}\text { Neonates without ROP } \\
\text { (n: 221) }\end{array}$} & \multirow{2}{*}{$\frac{p}{0.001}$} \\
\hline & 86 & $(86.9 \%)$ & 85 & $(38.5 \%)$ & \\
\hline Bronchopulmonary diseases * & 42 & $(42.4 \%)$ & 8 & $(3.6 \%)$ & 0.001 \\
\hline Cardiac diseases * & 33 & $(33.3 \%)$ & 16 & $(7.2 \%)$ & 0.001 \\
\hline Infections * & 8 & $(8.1 \%)$ & 5 & $(2.3 \%)$ & 0.027 \\
\hline Steroid Treatment $*$ & 4 & $(4 \%)$ & 0 & 0 & 0.009 \\
\hline Hydrocephaly * & 4 & $(4 \%)$ & 1 & $(0.5 \%)$ & 0.033 \\
\hline Transfusion & 2 & $(2 \%)$ & 1 & $(0.5 \%)$ & 0.227 \\
\hline Previous Surgery $*$ & 16 & $(16.2 \%)$ & 12 & $(5.4 \%)$ & 0.003 \\
\hline Jaundice & 17 & $(17.2 \%)$ & 28 & $(12.7 \%)$ & 0.370 \\
\hline Human milk intake ${ }^{*}$ & 79 & $(79.8 \%)$ & 214 & $(96.8 \%)$ & 0.001 \\
\hline
\end{tabular}

*Statistically significant risk factors.

on the development of ROP. Logistic regression analysis of the presented study revealed that; gestational age at birth, cardiac and pulmonary diseases, artificial ventilation support and breastfeeding time period were statistically significant risk factors effecting ROP development. The results of many studies involving aforementioned risk factors were similar to this study and excluding the oxygen supplement policy the only other risk factors determined in this study which can be modified is human breast milk. ${ }^{1-7,13-18}$

The effect of human breast milk on ROP development is a controversial issue in the literature. ${ }^{19-25}$ As far as we know, studies about the pathophysiological relationship between ROP and human breast milk are limited. ${ }^{24}$ ROP develops at two phases and the first phase is the hyperoxic phase. Hyperoxic phase is characterized with lack of insulinlike growth factor-1 (IGF-1) and the second hypoxic phase is characterized by increased vascular endothelial growth factor (VEGF) levels. ${ }^{32}$ The first phase is related with the third trimester of the gestation, at which IGF-1 levels increases in the maternal serum. ${ }^{33,34}$ Due to premature birth, the infants are deprived of maternal IGF-1 and many other factors like epidermal growth factor (EGF), heparinbinding EGF (HB-EGF), erythropoietin (Epo), nerve growth factor (NGF). EGF, HB-EGF, Epo, NGF. ${ }^{26-28}$ At that period, the infant liver is unable to produce IGF-1 and probably the aforementioned other bioactive factors cause the first pathophysiological stage to occur. $^{35}$ According to our study results we speculate that; premature infants, who have had the opportunity to receieve human breast milk for enough time, could complete the retinal vascular development and by-pass the first stage of ROP with the help of maternal IGF-1 found in the human breast milk. ${ }^{26-28}$ Several studies in the literature support this speculation by showing the association between the weight gain (prenatal and postnatal) and retinal vascularization, depending on the effect of IGF-1 by nutritional support. 36,37 This support is human breast milk. In our study human breast milk intake percentage was lower among infants at any stage of ROP compared to those without ROP $(79.8 \%, 96.8 \%$, respectively, $\mathrm{p}<0.001)$. Not only the effect of whether or not they were fed human breast milk, but also the duration of human breast milk intake had a significant effect on ROP development. This finding supports the idea that many other factors secreted into human breast milk at different time periods may also affect ROP development.

The importance of IGF-1 in the pathophysiology of ROP development was proven by Vanhaesebrouck et al. ${ }^{38}$ in their oxygen induced rat model study. Four day old pups which were given IGF-1 externally, did not develop ROP. Similarly, Hellstrom et al. ${ }^{39,40}$ proved that lower serum IGF-1 values are related with ROP development. Postnatal weight gain and human breast milk intake amount are found to 
Table II. Logistic Regression Analysis for the Risk Factors of ROP.

\begin{tabular}{lcccc}
\hline \multirow{2}{*}{ Risk factors } & Odds Ratio & Lower & Upper & $\mathrm{p}$ \\
\hline Gestational age* & 0.627 & 0.538 & 0.729 & $<0.001$ \\
Ventilation support* & 3.160 & 1.427 & 6.999 & 0.005 \\
Cardiac diseases* & 2.967 & 1.195 & 7.366 & 0.019 \\
Bronchopulmonary diseases* & 8.744 & 3.156 & 24.222 & $<0.001$ \\
Human milk intake time period* & 0.744 & 0.621 & 0.891 & 0.001 \\
Gender & 1.600 & 0.747 & 3.431 & 0.227 \\
Apgar scores & 0.526 & 0.254 & 1.089 & 0.084 \\
Birth weight & 0.999 & 0.998 & 1.000 & 0.133 \\
Only human milk & 0.762 & 0.112 & 5.175 & 0.781 \\
Human milk + formula feeding & 0.722 & 0.137 & 3.800 & 0.700 \\
Infections & 1.060 & 0.147 & 7.654 & 0.954 \\
Past Operations & 0.970 & 0.279 & 3.378 & 0.962 \\
Jaundice & 1.759 & 0.616 & 5.026 & 0.292 \\
\hline
\end{tabular}

* Statistically significant risk factors

be effective on ROP development in an oxygen induced rat model. ${ }^{36,41}$ From a clinical aspect; the importance of human breast milk for ROP development has been previously reported. ${ }^{19-25}$ A multicenter study evaluating the effect of human breast milk on ROP among other risk factors for 4 years, found that human breast milk prevents ROP. ${ }^{23}$ Similar to this study, Hylander et al. compared 283 formula and breast fed infants under 1500 grams and they concluded a lower incidence of ROP in breastfed infants. ${ }^{19} \mathrm{~A}$ meta-analysis comparing the relationship between human breast milk and ROP in several important studies concluded the preventive effect of human breast milk on ROP. ${ }^{24}$ Additionally, a recent systematic review and meta-analysis also evaluating the relation between human breast milk and ROP stated the protective effect of breast milk. ${ }^{25}$ Contrary to all of these reports; Heller et al. ${ }^{20}$ concluded that human breast milk intake was not associated with a decreased risk of ROP in extremely very low birth weight infants. Kao et al. ${ }^{22}$ also evaluated the antioxidant effect of human breast milk and bilirubin on ROP, but only high bilurubin levels were found to have a protective effect on ROP, contrary to our study. A common point to all of these studies including ours is that human breast milk is advised to prevent ROP. As far as we know from the literature, the presented study is the first investigating the effect of duration of human breast milk intake on ROP. This is important when we consider the dynamic pathophysiology of ROP and the changing ingredients of human breast milk by time.

This study additionally gives data concerning the rate of ROP for the western part of Turkey. Overall ROP cases at any stage was $31 \%$, ROP treated by laser was $5.9 \%$. The results are similar to other developing countries. $2,5,6,16,17$ Although approved guidelines for the diagnosis and treatment of ROP were used in our study, these guidelines did not include babies born at the 33rd-34th gestational weeks who needed laser treatment in our study. The National Neonatology and Ophthalmology Clinics of our country released a guideline for ROP screening and treatment in 2016. ${ }^{31}$ Therefore, guidelines for the development of ROP in developing countries should be modified according to their own data.

The limitations of our study were its retrospective nature and a small number of participants from a single center. Unfortunately, human breast milk and infant serum IGF-1 levels were not matched with the ROP stages and human breast milk volume, additionally knowledge concerning human breast milk features such as if it is fresh or frozen and also the content of the human breast milk 
could not be analyzed.

In conclusion; the result of this presented study reveals that human breast milk is highly important for preventing ROP, possibly due to IGF-1 existance. ${ }^{26-28}$ Further prospective studies are needed to clarify the relationship between IGF-1 and other possible factors found in human breast milk and ROP development. Human breast milk may be the best, safest and the cheapest medication for the prevention of ROP.

\section{REFERENCES}

1. Gilbert C. Retinopathy of prematurity: A global perspective of the epidemics, population of babies at risk and implications for control. Early Hum Dev 2008; 84: 77-82.

2. Fortes Filho JB, Eckert GU, Procianoy L, Barros CK, Procianoy RS. Incidence and risk factors for retinopathy of prematurity in very low and in extremely low birth weight infants in a unit-based approach in southern Brazil. Eye (Lond) 2009; 23: 25-30.

3. Sarikabadayi YU, Aydemir O, Ozen ZT, et al. Screening for retinopathy of prematurity in a large tertiary neonatal intensive care unit in Turkey: Frequency and risk factors. Ophthalmic Epidemiol 2011; 18: 269-274.

4. Alpay A, Uğurbaş SH. Incidence and risk factors for retinopathy of prematurity in the West Black Sea region, Turkey. Turk J Pediatr 2012; 54: 113-118.

5. Yau GSK, Lee JWY, Tam VTY, Liu CCL, Chu BCY, Yuen CYF. Incidence and risk factors for retinopathy of prematurity in extreme low birth weight Chinese infants. Int Ophthalmol 2015; 35: 365-373.

6. Park SH, Yum HR, Kim S, Lee YC. Retinopathy of prematurity in Korean infants with birthweight greater than 1500 g. Br J Ophthalmol 2016; 100: 834-838.

7. Bas AY, Koc E, Dilmen U; ROP Neonatal Study Group. Incidence and severity of retinopathy of prematurity in Turkey. Br J Ophthalmol 2015; 99: 1311-1314.

8. Good WV, Hardy RJ, Dobson V, et al; Early Treatment for Retinopathy of Prematurity Cooperative Group. Final visual acuity results in the early treatment for retinopathy of prematurity study. Arch Ophthalmol 2010; 128: 663-671.

9. VanderVeen DK, Bremer DL, Fellows RR, et al; Early Treatment for Retinopathy of Prematurity Cooperative Group. Prevalence and course of strabismus through age 6 years in participants of the Early Treatment for Retinopathy of Prematurity randomized trial. J AAPOS 2011; 15: 536-540.

10. Wu WC, Lin RI, Shih CP, et al. Visual acuity, optical components, and macular abnormalities in patients with a history of retinopathy of prematurity. Ophthalmology 2012; 119: 1907-1916.

11. Fielder A, Blencowe H, O'Connor A, Gilbert C. Impact of retinopathy of prematurity on ocular structures and visual functions. Arch Dis Child Fetal Neonatal Ed 2015; 100: F179-F184.
12. Vijayalakshmi P, Kara T, Gilbert C. Ocular morbidity associated with retinopathy of prematurity in treated and untreated eyes: A review of the literature and data from a tertiary eye-care center in southern India. Indian Pediatr 2016; 53(Suppl 2): S137-S145.

13. Akkoyun I, Oto S, Yilmaz G, et al. Risk factors in the development of mild and severe retinopathy of prematurity. J AAPOS 2006; 10: 449-453.

14. Thomas K, Shah PS, Canning R, Harrison A, Lee SK, Dow KE. Retinopathy of prematurity: Risk factors and variability in Canadian neonatal intensive care units. J Neonatal Perinatal Med 2015; 8: 207-214.

15. Slidsborg C, Jensen A, Forman JL, et al. Neonatal Risk Factors for Treatment-Demanding Retinopathy of Prematurity: A Danish National Study. Ophthalmology 2016; 123: 796-803.

16. Alajbegovic-Halimic J, Zvizdic D, Alimanovic-Halilovic E, Dodik I, Duvnjak S. Risk factors for retinopathy of prematurity in premature born children. Med Arhc 2015; 69: 409-413.

17. Jacob MK, Sawardekar KP, Ayoub HG, Busaidi IA Validation of the existing modified screening criteria for detection of all cases of Retinopathy of Prematurity in preterm babies - 11 year study from a governorate referral hospital in Oman. Saudi J Ophthalmol 2016; 30: $3-8$.

18. Kumar P, Sankar MJ, Deorari A, et al. Risk factors for severe retinopathy of prematurity in preterm low birth weight neonates. Indian J Pediatr 2011; 78: 812-816.

19. Hylander MA, Strobino DM, Pezzullo JC, Dhanireddy R. Association of human milk feedings with a reduction in retinopathy of prematurity among very low birthweight infants. J Perinatol 2001; 21: 356-362.

20. Heller CD, O'Shea M, Yao Q, et al; NICHD Neonatal Research Network. Human milk intake and retinopathy of prematurity in extremely low birth weight infants. Pediatrics 2007; 120: 1-9.

21. Okamoto T, Shirai M, Kokubo M, et al. Human milk reduces the risk of retinal detachment in extremely low-birthweight infants. Pediatr Int 2007; 49: 894-897.

22. Kao JS, Dawson JD, Murray JC, et al. Possible roles of bilirubin and breast milk in protection against retinopathy of prematurity. Acta Paediatr 2011; 100: 347-351.

23. Manzoni P, Stolfi I, Pedicino R, et al; Italian Task Force for the Study and Prevention of Neonatal Fungal Infections, Italian Society of Neonatology. Human milk feeding prevents retinopathy of prematurity (ROP) in preterm VLBW neonates. Early Hum Dev 2013; 89(Suppl 1): S64-S68.

24. Zhou J, Shukla VV, John D, Chen C. Human Milk Feeding as a Protective Factor for Retinopathy of Prematurity: A Meta-analysis. Pediatrics 2015; 136: e1576-e1586.

25. Bharwani SK, Green BF, Pezzullo JC, Bharwani SS, Dhanireddy R. Systematic review and meta-analysis of human milk intake and retinopathy of prematurity: A significant update. J Perinatol 2016; 36: 913-920. 
26. Gregory KE, Walker WA. Immunologic factors in human milk and disease prevention in the preterm infant. Curr Pediatr Rep 2013; 1: 10.1007/s40124-013-0028-2.

27. Ballard O, Morrow AL. Human milk composition: Nutrients and bioactive factors. Pediatr Clin North Am 2013; 60: 49-74.

28. Kon IY, Shilina NM, Gmoshinskaya MV, Ivanushkina TA. The study of breast milk IGF-1, leptin, ghrelin and adiponectin levels as possible reasons of high weight gain in breast-fed infants. Ann Nutr Metab 2014; 65: 317-323.

29. The International Classification of Retinopathy of Prematurity revisited. An International Committee for the Classification of Retinopathy of Prematurity. Arch Ophthalmol 2005; 123: 991-999.

30. Revised indications for the treatment of retinopathy of prematurity: Results of the early treatment for retinopathy of prematurity randomized trial. Early Treatment for Retinopathy of Prematurity Cooperative Group. Arch Ophthalmol 2003; 121: 1684-1696.

31. Koç E, Baş AY, Özdek Ș, Ovalı F, Başmak H; TOD ROP Komisyonu, TND - ROP Çalışma Grubu. Türkiye Prematüre Retinopatisi Rehberi 2016.

32. Hellström A, Smith LE, Dammann O. Retinopathy of prematurity. Lancet 2013; 382: 1445-1457.

33. Caufriez A, Frankenne F, Englert Y, et al. Placental growth hormone as a potential regulator of maternal IGF-I during human pregnancy. Am J Physiol 1990; 258(6 Pt 1): E1014-E1019.

34. Langford K, Nicolaides K, Miell JP. Maternal and fetal insulin-like growth factors and their binding proteins in the second and third trimesters of human pregnancy. Human Reprod 1998; 13: 1389-1393.
35. Engström E, Niklasson A, Wikland KA, Ewald U, Hellström A. The role of maternal factors, postnatal nutrition, weight gain, and gender in regulation of serum IGF-I among preterm infants. Pediatr Res 2005; 57: 605-610.

36. Stahl A, Chen J, Sapieha P, et al. Postnatal weight gain modifies severity and functional outcome of oxygeninduced proliferative retinopathy. Am J Pathol 2010; 177: 2715-2723.

37. Hansen-Pupp I, Löfqvist C, Polberger S, et al. Influence of insulin-like growth factor I and nutrition during phases of postnatal growth in very preterm infants. Pediatr Res 2011; 69(5 Pt 1): 448-453.

38. Vanhaesebrouck S, Daniëls H, Moons L, Vanhole C, Carmeliet P, De Zegher F. Oxygen-induced retinopathy in mice: Amplification by neonatal IGF-I deficit and attenuation by IGF-I administration. Pediatr Res 2009; 65: $307-310$.

39. Hellström A, Engström E, Hard AL, et al. Postnatal serum insulin-like growth factor I deficiency is associated with retinopathy of prematurity and other complications of premature birth. Pediatrics 2003; 112: 1016-1020.

40. Hellstrom A, Perruzzi C, Ju M, et al. Low IGF-I suppresses VEGF-survival signaling in retinal endothelial cells: Direct correlation with clinical retinopathy of prematurity. Proc Natl Acad Sci USA 2001; 98: 5804-5808.

41. Matsubara M, Saito Y, Nakanishi-Ueda T, et al. Influence of the difference of breastfeeding volume on a rat model of oxygen-induced retinopathy. J Clin Biochem Nutr 2014; 55: 129-134. 